\title{
Technology acceptability for medical assistance
}

\author{
Martina Ziefle \\ Communication Science, RWTH Aachen \\ Human Technology Centre \\ Aachen, Germany \\ ziefle@humtec.rwth-aachen.de
}

\author{
Wiktoria Wilkowska \\ Communication Science, RWTH Aachen \\ Human Technology Centre \\ Aachen, Germany \\ wilkowska@humtec.rwth-aachen.de
}

\begin{abstract}
In this research we examine the age-specific acceptance motives of medical assistive technologies assessing the general openness of using these technologies as well as estimating potential barriers, which may impede a successful rollout. 122 respondents (20 - 80 years) participated in a survey, in which they were asked to evaluate the pros and cons of the usage of medical assistive technologies, acceptance motives and potential utilization barriers. In order to understand the complex nature of acceptance, personal variables (age, technology generation gender) as well as participants' learning history with technology (technical experience, subjective technical confidence and general attitudes towards the usage of technologies) were related to each other. Outcomes show that, overall, there is a quite positive motivation regarding the usage of medical technology, though, the perceived usage barriers are weighted more decisive for the acceptability of medical technology than the positively evaluated using motives. Overall, it was revealed that acceptance issues should be considered in order to proactively design a successful rollout of medical technologies.
\end{abstract}

Keywords: medical technology; ICT; age; gender; user diversity

\section{INTRODUCTION}

Nowadays, the number of old and frail people increases continuously and there is incremental need for medical care in the near future, e.g. [1] [2] [3]. In contrast to this increased need for medical care, there are serious shortcomings, because of the increased life expectancy and the improved health care. At the same time, considerable bottlenecks arise from the fact that increasingly fewer people are present, which may take over the nursing. Aggravating, we face supply shortfalls regarding societal health insurance funds [2]. In order to master the exigent requirements of an aging society, improvements in information and communication technologies (ICT) as well as developments in medical engineering are indispensable to offer novel or improved possibilities for medical diagnosis, therapy, treatments and rehabilitation possibilities [4] [5] [6].

So far, research on medical technology is mostly dominated by technical, medical and economic disciplines. The same applies for developments of medical products, which are guided by medical necessity, technical feasibility, and economic interest. In contrast, aspects of humans' technology acceptance as well as the detailed study and understanding of using motives and barriers are disregarded within technical development. Though, medical technology - especially in the home-care and rehabilitation sector - can only fully deploy its huge potential for graying societies, if acceptance issues of medical applications are adequately considered and implemented into design. In our opinion, the lack of

Permission to make digital or hard copies of all or part of this work for personal or classroom use is granted without fee provided that copies are not made or distributed for profit or commercial advantage and that copies bear this notice and the full citation on the first page. To copy otherwise, to republish, to post on servers or to redistribute to lists, requires prior specific permission and/or a fee. PERVASIVEHEALTH 2010, March 22-25, Munchen, Germany

Copyright (C) 2010 ICST 978-963-9799-89-9

DOI 10.4108/ICST.PERVASIVEHEALTH2010.8859 networking among the disciplines and the missing transfer of knowledge across them during academic education have hindered the creation of truly user-oriented electronic health systems, so far. In addition, the knowledge about the antecedents of electronic health acceptance and utilization behavior on the user side is restricted. This is due to several crucial factors:

Aging diversity: One factor in this context is that aging itself represents a highly complex process [7] [8] [9]. Not all users age in the same way, and the onset of aging and frail processes as well as the consequences of the decrease show considerable differences across humans [10] [11] [12]. Another factor that is likely to severely influence older adults' acceptance of technology is that aged users were educated in times when technical products were far less ubiquitous and much less complex than current devices. A mental model of how technology works, built in a former time, potentially interferes with, or at least is not sufficient for proper interaction with technology. As a consequence, the previous experience is also decisive for satisfying acceptance of devices. This fact is aggravating the situation especially for seniors, as the understanding of how technology works is to a large extent formed by upbringing and cultural factors [9] [12] [13] [14]. The subjective technical confidence (STC) is also discussed as one of the major factors of technology acceptance and system usage. The STC is an individual belief in one's own ability to solve technical problems [15]. Studies [9] [14] [16] [17] [18] have shown that high scores in computer self-efficacy and technical self confidence are related to performance and technology acceptance, especially in older users, whose selfefficacy is usually lower than the technical self-confidence of younger users.

Specificity of technology acceptance: Technology acceptance is examined for more than 25 years now and describes the approval, favorable reception and ongoing use of newly introduced devices and systems. Peoples' acceptance of technology is predominating the public discourse and the scientific discussion especially in times of technological cycles, in which new technologies are penetrating into personal and working environments. In the 1980ies and 1990ies, alongside with the ubiquitous introduction of personal computers, there was a boom of research dealing with technology acceptance. As technology cycles are increasingly faster, technology acceptance continued to be a key research issue.

The majority of approaches dealing with technology acceptance refer to the acceptance of ICT-technologies in a job-related context [10] [19] [20] [21]. Theories of technology acceptance [19] [20] [21] consider mainly two key components 
of technology acceptance: the perceived usefulness (PU) and the perceived ease of use (PEoU) as key determinants of individuals' intention to use a technical system. However, one of the main criticisms of these models was that external factors such as the influence of individual user variables on technology acceptance were almost completely disregarded. The most recent development within acceptance modeling represents the UTAUT model (Unified Theory of Acceptance and Usage of Technology) [21], which assumes performance expectancy, effort expectancy, social influence, and facilitating conditions as key constructs for technology usage intention and behavior. Additionally, individual variables (gender, age, experience, and voluntariness of use) are assumed to mediate the impact of those constructs on usage intention and behavior.

Another, in the here addressed context, problematical characteristic of existing technology acceptance models is that approaches exclusively focus on acceptance patterns of ICT, and they are predominantly job-related. A direct transfer of their assumptions to the acceptance of medical technology is highly disputable, though, this has not been fully analyzed yet. Up to now, only a few existing studies investigated the special nature of acceptance regarding medical technology [10] [22] [23] [24] [25] [26]. However, it is quite reasonable to assume that the acceptance of medical technology distinctly differs from acceptance-patterns of ICT for several reasons: First, medical devices are used not just for fun but because of (critical) health states. Also, beyond its importance for patients' safety and the feeling of being safe, medical technology refers to "taboo-related" areas, which are associated with disease and illness. Second, recent studies show that medical monitoring is often perceived as breaking into persons' intimacy and privacy spheres and often lead to a feeling of being permanently controlled. Interestingly, this is not the case in ICT technologies, even though the technology characteristics of e.g. mobile phones are the very same.

Concluding, there is a considerable need to explore and to understand the components contributing to users' acceptance of electronic health technologies in order to find alternative health care methods - in comparison and in addition to the traditional visit to the doctor's office - which meet especially the distinctive needs of older adults, and allow them to keep up an independent living at home.

\section{A. Research Model and Aim}

The current paper aimed for an explorative study of different motives and/or perceived obstacles to use medical technologies. A user-centered approach was pursued, which considered the characteristics of a highly heterogeneous user group. In order to examine a large number of participants and to consider the diversity within the older age group, the questionnaire-method was chosen.

We assumed that the real impulse for medical assistance usage is influenced by different factors. Firstly, the motives are related to perceived advantages and gains (pro arguments), which support the positive attitude towards medical technology. However, disadvantages and barriers (contra arguments) can also overshadow the usage, and, as a consequence, they may provoke averseness to use and to accept medical assistance. Secondly, peoples' motives to use medical technologies were assumed to interact with users characteristics regarding technical learning history with ICT, and also, to be influenced by the resulting technical self-confidence. Thirdly, persons' age affects medical technology usage. We assume that different age groups might have different reasons to accept or reject medical technology. Beyond age as a biological factor, ageing effects might be also referable to individuals' technological upbringing. Thus, age is also another term for technology generation, meaning that the prototypic technology model, prevailing at the respective time period, biases the acceptance of current technology. According to [27] [29], we differentiate three different technology generations: the earlytechnical generation (65+ years), the household revolution generation $(45+$ years $)$, and the computer generation $(20+$ years). Additionally, gender effects were analyzed across generations, as they frequently provoke differently colored biases regarding technical matters. Figure 1 illustrates a schematic research model, which conceptualizes the relation of the different factors, which are assumed to affect the using motives for medical assistance.

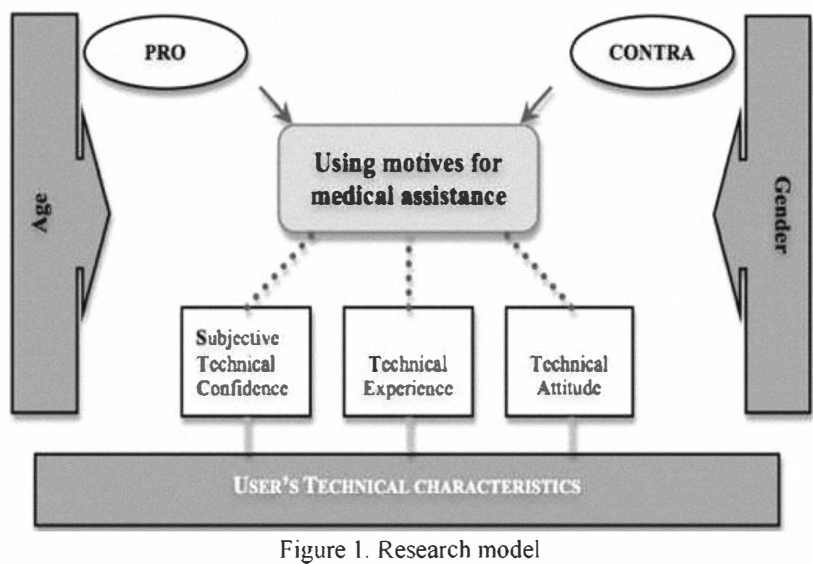

According to the proposed model following hypotheses are specified:

H1: Technology generations differ within their level of technical experience, the attitude towards technology in general, and the technical self-confidence. Generally, it is assumed that younger users (computer generation) show higher values in these criteria than older generations (household and early technical generation).

H2: Women show lower levels of technical experience and technical self-confidence, and, in general, less positive attitude towards technology.

H3: Users with a higher technical experience show higher acceptability towards usage of medical technology.

H4: Users with a higher level of STC show higher acceptability of medical technology.

\section{METHODOLOGY}

\section{A. Participants}

The data of $\mathrm{N}=122$ participants, aged between 20 and 80 years $(46 \%$ female) were analyzed in this study. The sample was split in three age groups, and technology generations, respectively: the first group is aged between 20 and 35 years 
and consists 43 persons $(\mathrm{M}=29, \mathrm{SD}=3.9 ; 40 \%$ female); the second age group $(n=41)$ compose males $(44 \%)$ and females $(56 \%)$ at the age between 36 and 54 years $(\mathrm{M}=45.4, \mathrm{SD}=$ $5.3)$; and the third age group contains 38 respondents aged between 55 and 80 years $(\mathrm{M}=64.3, \mathrm{SD}=6.9)$ with the proportion of $42 \%$ females and $58 \%$ males. The intention in the recruitment procedure was to survey differently aged but healthy people in order to explore and to compare their opinions (motives and barriers) about future electronic solutions in the healthcare and their intended usage behavior. The participants were reached on different ways. Many of the computer generation respondents were university students of various academic fields (technical disciplines, social science, and humanities), and also persons being in vocational training or serving an apprenticeship (electricians, insurance salesman, bakers). Other respondents - those classified to the household and the early-technical generations - were reached partially through the social network of the authors and partially by advertisement in a local newspaper as well as through seniors' social contacts, and covered a broad range of professions too (e.g., administrative officers, secretaries, teachers, accountants, nurses, engineers, physicians, healthcare workers).

\section{B. The Questionnaire}

In order to collect comprehensive opinions and to reflect them according to the three technology generations we examined a large number of participants choosing the questionnaire-method.

The questionnaire was arranged in three main sections. The first part included demographic data regarding participants' age, gender, educational level and (previous) profession. The second section applied to person's experience with and to technology attitude (TA), and also to the degree to which a person believes in the own competence to solve technical problem (STC) [15]. Assessing experience, the usagefrequency of common ICT-devices (e.g., mobile phone, PC, video/digital camera, navigation system/GPS), and the perceived usability of these in private and working context were comprised. Items regarding TA covered both positive (e.g., "I am very interested in technical devices") and negative statements (e.g., "I regard technical devices with suspicion") towards technology. The attitude items (STC and TA) had to be answered on a six-point Likert scale ranging from 1 (do not agree at all) to 6 (fully agree). The third section referenced to the different motives for (future) usage of medical devices (e.g., blood pressure meter, blood sugar meter). At the beginning of this questionnaire part respondents were briefed to empathize with the necessity to daily collect some vital bodily functions (e.g., blood sugar level, pulse, body temperature). Participants were instructed to state if they would accept technologies like these and to report the most important pros and cons regarding the usefulness of these technologies. In this way it should have been assured that all participants - the hale and hearty too - feel concerned by and fill in the subsequent questions. The pros and cons with regard to medical technology usage had to be rated on a five-point Likert scale ranging from 1 (do not agree) to 5 (fully agree).

Before administering the questionnaire it was revised by a sample of different aged adults $(n=12)$ and by a usability expert with respect to issues of comprehensibility and wording of items. The fill in of the final version of the questionnaire took 20-30 minutes.

\section{Research Variables}

As independent variables (1) participants' age (comparing younger, middle and older aged persons and technology generation (computer, household and early technical generation, [27] [29] [30] [31]) and (2) gender (contrasting female and male respondents) were taken into consideration in the present study. Moderating variables were defined as the learning history with technology, i.e. technical experience, technical self-confidence and attitudes towards the usage of technology (both, positive and negative aspects).

\section{RESUlTS}

Results were analyzed by ANOVA - procedures (differences between age/generation groups and gender) and bivariate correlation analyses to assess the interrelation between factors, and variables. The level of significance was set at $5 \%$. Outcomes within the less restrictive significance level of $10 \%$ are referred to as marginally significant.

The result section is structured as follows. A first analysis regards the question, whether there are effects of age and gender within the moderating variables (STC, technical expertise and attitudes towards technology). Then, findings regarding the using motives and utilization barriers in the different age and gender groups are reported. Finally, we detail the interrelation of these variables on the acceptance to use medical technologies.

\section{A. Technical Self-Confidence, Technical Experience and Attitudes towards Technology}

A first analysis considers the question whether we can find age and gender effects within moderating variables (Figure 2).

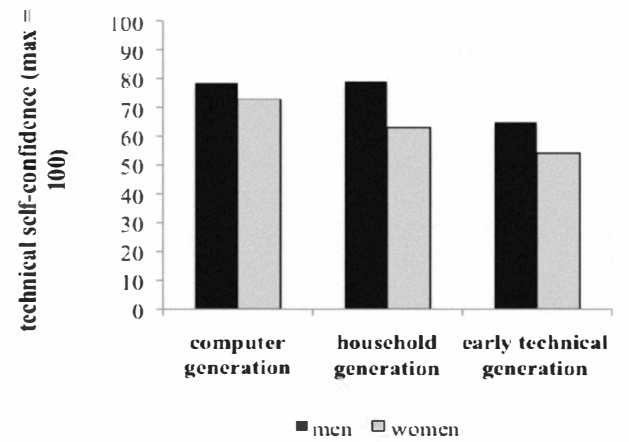

Figure 2. Technical self-confidence levels in age and gender groups

Regarding the STC, a significant main effect of age ( $F$ $(2,117)=13.5 ; p<0,05)$ and gender was found $(F(1,117)=$ $17.6 ; \mathrm{p}<0,05)$, while there was no interacting effect of both factors. Thus, as illustrated in Figure 2, the levels of technical self-confidence are lower in women (independently of age) compared to men, and also, the levels of technical selfconfidence decrease with increasing age.

The next focus is directed to the experience with technical devices. When asked about the technical experience (in terms of usage frequency of technical devices), female respondents 
reported a significantly lower experience than males ( $\mathrm{F}(1,117)$ $=9.4 ; \mathrm{p}<0,05)$. Also, a significant age effect was found, revealing a decreasing technical experience with increasing age $(\mathrm{F}(2,117)=11.6 ; \mathrm{p}<0,05)$. A marginally significant interacting effect of gender and age $(F(2,117)=2.6 ; p<0,1)$ indicates that especially older women have the lowest level of technical experience (Figure 3).

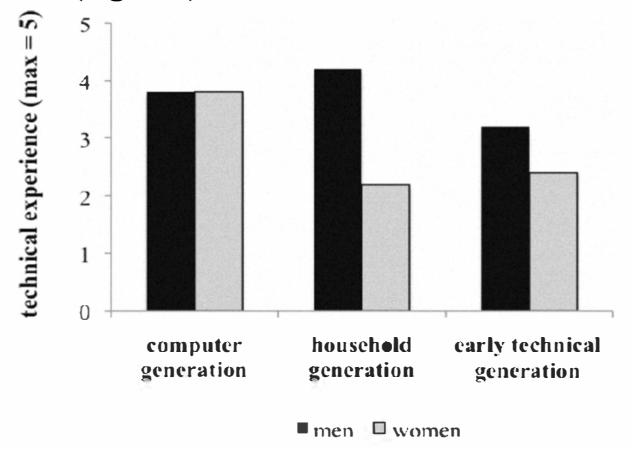

Figure 3. Technical experience

Regarding the attitudes towards commonly used technology, we differentiated between negative and positive tendencies in order to get a detailed insight into technology attitudes. With respect to the positive attitudes (high interest in and a high fascination by technology), a significant age effect $(\mathrm{F}(2,117)=12.8 ; \mathrm{p}<0,05)$ as well as a highly significant gender effect $(F(1,117)=24.8 ; p<0,05)$ was found. No interacting effect was present. This finding reveals that men show distinctly more positive biases towards technology than women (independently from age). And also, the positive attitude towards technology decreases with increasing age of respondents (Figure 4).

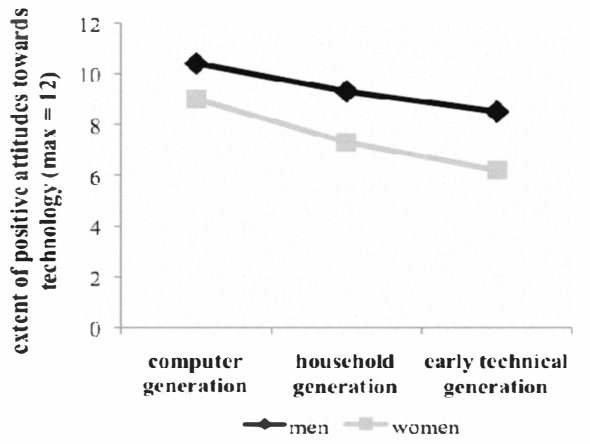

Figure 4. Extent of positive attitudes towards technology in both age and gender groups

It is a highly interesting finding that neither age nor gender effects could be detected when focusing on negative attitudes (averseness and suspiciousness towards technology). Apparently, the negative bias is equally present or absent across age and gender groups (Figure 5).

From a methodological point of view, it is highly useful to differentiate between positive and negative impressions in the context of technology usage, because there is no overall general attitude towards technology, but a very differential picture, which is composed out of a different extent of negative and positive bias when using technology.

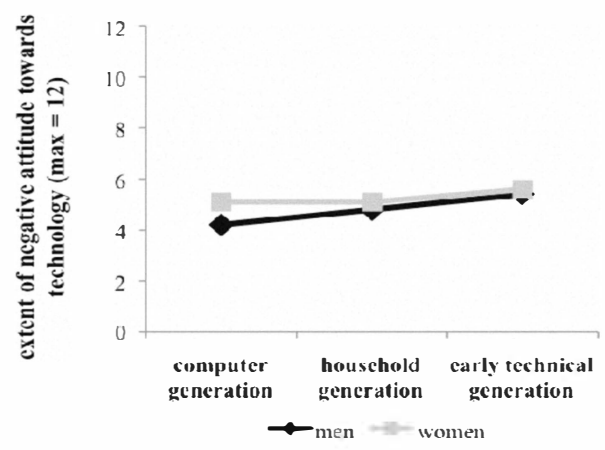

Figure 5. Extent of negative attitudes towards technology in both age and gender groups

All moderating variables are significantly correlated and show strong connectivity (Table 1). As can be seen there, the technical self-confidence is lower in aged persons and in women. With increasing age, technical experience is lower. Individuals with a higher level of experience show a higher technical self-confidence.

With respect to the question, how technologies are evaluated and how this is related to individual factors, it is especially insightful that the extent of technical self-confidence is highly positive correlated with the presence of positive technical attitudes $(\mathrm{r}=.77 ; \mathrm{p}<0,01)$ and highly negatively associated with a negative bias towards technology $(\mathrm{r}=-.53$; $\mathrm{p}<0,01)$. It shows that the self-confidence is a potent mediator of the general openness to technology.

TABLE I. INTERCORRELA TIONS OF MODERATING VARIABLES $(\mathrm{N}=122)$. BOLD VALUES ARE SIGNIFICANT $(* \mathrm{P}<0,05 ; * * \mathrm{P}<0,01)$. STC $=$ TECHNICAL SELF-CONFIDENCE; TA $=$ TECHNICAL ATTITUDE

\begin{tabular}{|l|c|c|c|c|c|}
\hline & Gender & STC & $\begin{array}{c}\text { Technical } \\
\text { Experience }\end{array}$ & $\begin{array}{c}\text { positive } \\
\text { TA }\end{array}$ & $\begin{array}{c}\text { negative } \\
\text { TA }\end{array}$ \\
\hline Age & -- & $-.43^{* *}$ & $-.43^{* *}$ & $-.43^{* *}$ & .19 \\
\hline Gender & 1 & $-.35^{* *}$ & $.25^{*}$ & $-.41^{* *}$ & .17 \\
\hline STC & & 1 & $.39^{* *}$ & $.77^{* *}$ &.$- .53^{* *}$ \\
\hline $\begin{array}{l}\text { Technical } \\
\text { Experience }\end{array}$ & & & 1 & $.32^{* *}$ & $-.25^{*}$ \\
\hline $\begin{array}{l}\text { positive } \\
\text { TA }\end{array}$ & & & & 1 & $-.49^{* *}$ \\
\hline $\begin{array}{l}\text { negative } \\
\text { TA }\end{array}$ & & & & & 1 \\
\hline
\end{tabular}

B. Using Motives (pros and cons) Towards Medical Technology

In this section we analyze age and gender effects regarding the usage of medical technology.

Among the pros (Table 2) and cons (Table 3), participants rated the degree of confirmation or rejection to the different statements. The statements were taken from previous research [23] [24] [27] in which focus groups with older adults were conducted and the main arguments in both, pros and cons were collected. Meeting demands of quality criteria, reliability analyses were carried out. Cronbach's Alpha values reached sufficient values (pro arguments: $\alpha=.84$; contra arguments: $\alpha=$ $.90)$. 
TABLE II. PROS FOR THE USAGE OF MEDICAL TECHNOLOGY

\begin{tabular}{l}
\hline I would use medical technology... (max $=65)$ \\
$\ldots$ if s.o. gives me a detailed instruction of how to use the system \\
$\ldots$ if I would be convinced of the system security \\
$\ldots$ if I would be convinced of the system safety \\
$\ldots$ if my health state deserves it \\
$\ldots$ if my doctor recommends the system usage to me \\
$\ldots$ if I could ask for help whenever I have usability problems \\
$\ldots$ if I am convinced of data privacy \\
$\ldots$ if I could control the transmission of the data \\
$\ldots$ if the system is controlled by a accredited institution \\
$\ldots$ because in case of emergency the system facilitates medical help \\
$\ldots$ because I am informed regularly about my health condition \\
$\ldots$ because it is comfortable for me to control my health state a home \\
$\ldots$ because the system is able to warn timely in case of emergency
\end{tabular}

Overall, 65 points could be reached at most, representing the highest possible approval.

TABLE III. CONS AGAINST THE USAGE OF MEDICAL TECHNOLOGY

I would not use medical technology... $(\max =65)$
$\ldots$ if there is no absolute urgency
$\ldots$ because I fear that unauthorized persons gain insights into my health state
$\ldots$ because I do not want other persons get to know that I need medical help
$\ldots$ because I do not like to feel controlled by a technical device
$\ldots$ because I do not want to be remembered that I am ill
$\ldots$ because I truly prefer personal medical assistance of caregivers
$\ldots$ because I usually have issues with usage of technical devices
$\ldots$ because I think that technology assistance is too impersonal
$\ldots$ because technology already penetrates all fields of private life
$\ldots$ because I do not want to continuously learn to handle new technology
$\ldots$ because I do not want to be controlled by technology
$\ldots$ because I do not like the feeling of technology dependency
... because I do not trust the reliability of technology

In order to get an overview, all items (the pros and the cons, respectively) were summarized and the means were used for further analyses.

In Figure 6 the extent of pro arguments towards the usage of medical technology in different age generations and with respect to the both gender groups is illustrated.

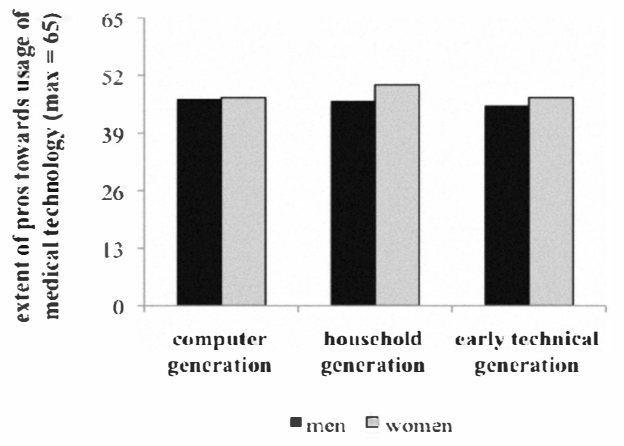

Figure 6. Extent of pro arguments towards the usage of medical technology in both age and gender groups

As can be seen, no age effect is present showing that the slightly positive attitude towards usage of medical technology (means range at about 45 out of maximum 65 points) does not vary across technology generations. However, a significant gender effect was detected $(F(1,117)=4.2 ; p<0,05)$, revealing women to be more positive towards the usage of medical technology compared to male respondents.

When focusing on the contra arguments against the usage of medical technology (Figure 7), significant age effect was present $(\mathrm{F}(2,117)=4.6 ; \mathrm{p}<0,05)$. Gender effect, in contrast, could not be detected.

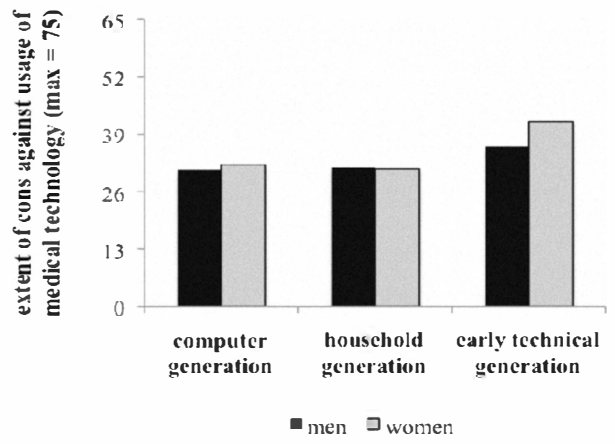

Figure 7. Extent of contra arguments against the usage of medical technology in both age and gender groups

Two findings are especially noteworthy in this context. First of all, the oldest generation, the early technical generation, reveals to be the most critical and negative towards the usage of medical technology. Apparently, the perceived closeness to the need of medical assistance does not necessarily lead to a higher acceptance. In the contrary, the perceived closeness evokes especially critical and discerning attitudes respecting medical technology. This result is somewhat ironic considering the higher probability of chronic illnesses and the requirement to use medical assistance with increasing age.

The second finding is that - overall - the extent of cons is generally lower than the extent of pros towards the medical technology usage. In short: basically, respondents show independently of age and technology generation - more willing than reluctant intention to use medical assistance.

\section{The Interrelations of Research Variables and the Importance of Users' Charateristics for the Intention to Use Medical Technology}

We started this research with the basic question, to which extent users' acceptance of medical technologies is influenced by individual characteristics (age/technology generation and gender) as well as by the learning history with technology (technical experience, technical self-confidence, attitudes towards the usage of technology). Based on the present research we now can a) furnish the assumed relationships with quantitative data and b) identify the key player on users' adults' acceptance.

In Table 4, the correlation outcomes are visualized. In contrast to our expectations, according to which individual factors and 
technical learning history would be decisive for the acceptance of medical assistance, this cannot be fully confirmed.

Basically it is striking that it is not primarily the usage motivation in terms of pro arguments, which are related to individual variables (age, gender) and the learning history with technology. Rather, only the negative using motives, the contra arguments were the key factors associated with individual factors. As can be seen in Table 4, the reported usage barriers (cons) are significantly impacted by the users' age $(\mathrm{r}=0.24 ; \mathrm{p}<0,05)$. Thus, the older participants, the more contra arguments were given. Usage barriers are also negatively correlated to the level of technical self-confidence $(\mathrm{r}=-0.31 ; \mathrm{p}<0,05)$ and the level of technical experience $(\mathrm{r}=$ $0.39 ; \mathrm{p}<0,05)$. The lower individuals technical self-confidence and technical experience, the more negative is the using motivation for medical assistance. In addition, individuals who show a negative attitude to medical assistance also have negative attitudes towards technology in general $(\mathrm{r}=0.37$; $\mathrm{p}<0,05$ ). In other words, the lower persons' perceived technical confidence and the experience with common technology, and the higher the extent of negative attitudes towards the usage of technology in general (averseness and suspiciousness towards technology), the lower is the acceptability of (future) medical technology usage. Gender, in contrast to age, was not significantly interrelated with the acceptability of medical assistance, neither regarding the using motives nor the usage barriers. It is noteworthy, that the usage barriers were identified to be more decisive and thus more essential to predict the general acceptability of medical technology, in contrast to the positive expectations connected to the usage of medical technology.

It shows that key components discussed to predict acceptance of ICT technology are qualitatively different from the acceptance of medical technology. The strong weight and the influence of negative characteristics as well as the motivation to avoid these negative attitudes for persons' own life is a severe impeding factor for a successful rollout. Apparently, acceptance of medical technology is not perceived as a whole, but rather reveals to be a complex product out of weighed pros and cons. From a methodological point of view therefore, is necessary to take the pros and the cons into account in order to get an understanding of both sides of acceptance.

TABLE IV. INTERCORRELATIONS OF VARIABLES $(\mathrm{N}=122)$. BOLD VALUES ARE SIGNIFICANT $(* \mathrm{p}<0,05 ; * * \mathrm{p}<0,01)$. STC $=$ TECHNICAL SELF-CONFIDENCE;

TA = TECHNICAL ATTITUDE; TE $=$ TECHNICAL EXPERIENCE; $\mathrm{MT}=$ MEDICAL TECHNOLOGY

\begin{tabular}{|c|c|c|c|c|c|c|}
\hline & STC & TE & $\begin{array}{c}\text { positive } \\
\text { TA } \\
\end{array}$ & $\begin{array}{c}\text { negative } \\
\text { TA }\end{array}$ & $\begin{array}{l}\text { Pros } \\
\text { MT }\end{array}$ & $\begin{array}{l}\text { Cons } \\
\text { MT }\end{array}$ \\
\hline Age & $-.43^{* *}$ & $-.43 * *$ & $-.43^{* *}$ & .19 & -.01 & $.24^{* *}$ \\
\hline Gender & $-.35^{* *}$ & $.25^{*}$ & $-.41 * *$ & .17 & .14 & .10 \\
\hline STC & 1 & $.39^{* *}$ & $.77 * *$ & $-.53^{* *}$ & -.03 & $-.31^{* *}$ \\
\hline TE & & 1 & $.32^{* *}$ & $-.25^{*}$ & .03 & $-.39^{* *}$ \\
\hline $\begin{array}{l}\text { positive } \\
\text { TA }\end{array}$ & & & 1 & $-.49 * *$ & -.13 & $-.19^{*}$ \\
\hline $\begin{array}{l}\text { negative } \\
\text { TA }\end{array}$ & & & & 1 & -.01 & $.37 * *$ \\
\hline Pros & & & & & 1 & -.18 \\
\hline
\end{tabular}

\begin{tabular}{|l|l|l|l|l|l|l|}
\hline MT & & & & & & \\
\hline $\begin{array}{l}\text { Cons } \\
\text { MT }\end{array}$ & & & & & & 1 \\
\hline
\end{tabular}

\section{DISCUSSION}

The aim of the present study was to analyze the contribution of generation and gender specific motive patterns for the intention to use medical technology. Therefore, we determined acceptance for medical technology, differentiated in using motives (pro arguments) and using barriers (contra arguments) in each of three technical generations: the earlytechnical generation, the household revolution generation, and the computer generation. In order to identify to which extent the learning history with technology impacts the acceptability of medical technical assistance, respondents' level of previous experience with common used technology, their technical selfconfidence, and their positive (interest, fascination) vs. negative (averseness, distrust in technology) attitudes towards technology usage in general were assessed and related to the acceptance of medical technology.

In order to empirically test our hypothetical considerations, 122 participants were examined by the questionnaire method. Before findings of the research are discussed within implications for research, application and future research demands, it should be noted that the topic "acceptability of medical technology" is highly sensitive. People asked to participate in this research showed a high interest for the topic and a high willingness to participate, independently of generation and gender. Apparently, a high public awareness for the societal needs of medical technology is present as well as a high motivation to express own opinions and fears connected to its usage.

First of all, it should be stressed that people's willingness to use medical technology - if necessary - is larger than the perceived using barriers, as can be taken from the overall higher positive compared to the negative ratings.

However, it is of considerable impact that it is the oldest generation (early technical generation) that shows the highest aloofness to use medical technology and express the strongest using barriers, the strongest averseness and distrust towards medical technology. Considering that it is exactly this group, which most probable needs to use medical technology in the near future, this finding is alarming. It shows that older adults' requirements should be especially regarded within design approaches (asking for their individual needs and wants) and also respecting an age-sensitive communication strategy.

To date, we do not have a specific communication concept not to mention any awareness that there is a considerable need for this. Rather, designers seem to believe that older users will automatically and easily accept medical technology out of pragmatic reasons. It seems to be a common belief that older and frail users must want to use medical devices in order to keep independency and mobility, and that they will use this technology anyway, as they do not have any alternatives. Considering that "aging" is not a unique phenomenon, but entails different developmental processes, attitudes, and biographical influences, this assumption seems rather naïve. Accordingly, recent data insistently show that older adults' 
individual aging concepts and their norms regarding the "value to live long" are quite homogeneous [27] [39].

Even though it might be contra-intuitive out of the perspective of a young and healthy person, the value of life extending by means of medical technology might be evaluated quite differently out of the perspective of a person, which is already old, or frail, or even chronically ill [27] [38]. In addition, we should be aware that aging concepts, and the perceived usefulness of medical technology for an independent living of older persons might be a rather culturedependent view. Yet, hardly any study was concerned with the impact of different cultures and societal aging concepts on the acceptance of medical technology, even though this is of urgent importance from our perspective.

People developing and designing medical technology should take older adults' rather reluctant attitude in this regard more seriously. It should be kept in mind that any devices' technical genius and the promised advantage for users' daily needs can only be recognized and highly valued, if human characteristics and cognitive specificities are adequately taken into account. Thus, whenever the knowledge of both, the technical and the human factors is incorporated into current design, technology may meet the demands of users, designers and manufacturers at the same time.

Melenhorst and coworkers [18], for example, explain the reluctance of older adults to weigh technological devices as "useful" by the lack of perceived advantages or benefits. The perceived context-related benefit, however, is a major motivation for using or not using a device. Older adults tend to be present-oriented and, consequently, do not necessarily see the need to evaluate technical devices as useful, which will be possibly used in future. The expected gain of the device may be perceived as not worth the trouble (learning cost, frustration and anger about a suboptimal usability).

This present-oriented attitude possibly reduces also older adults' preparedness to learn something new and to intensively deal with a new technology. Thus, for older adults, appropriate information about the benefits of technical devices represents an important determinant for using them. Provided benefits are valued sufficiently high, and they may overcome their reluctance and their susceptibility to effects of low usability and interface complexity. Taken this for granted, the perceived usefulness represents asymmetrically more important facet of technology acceptance for older adults in comparison to the perceived ease of device using. Training the skills to handle a new technology should therefore involve more information about its specific benefits from users' perspective. Such additionally notice would probably enhance older adults' motivation to use technology, and by this, enhance their experience with technology, which would have a positive effect on the acceptability of medical technology [27] [28] [32] [33] [34].

However, this study represents only a first insight in a highly complex phenomenon. Thus, there are limitations of this research, which should be picked up in future studies.

Besides individual variables such as age and gender we assume that further health-related constructs (coping, compliance) need to be considered in a global theoretical model of medical technology acceptance and utilization behaviour. Individuals' coping-strategies refer to specific psychological and behavioural efforts that people employ to master, tolerate, reduce or minimize stressful events. They can be categorized in problem-solving oriented vs. emotionfocused, active or avoidant strategies, and were found to affect physical and psychological health outcomes [35] [36]. Furthermore, the construct of compliance has been adopted to describe the degree to which patients follow their provider's recommendations. Modern definitions of compliance emphasize a proactive patient involvement instead of a patient-provider hierarchy [37].

Moreover, current approaches of technology acceptance describe a static perspective of technology acceptance, whereas the acceptance of medical applications might have many dynamic components, which are influenced not alone by disease-related changes in health state, but also by different coping strategies and compliance behaviour. Therefore, future approaches should aim at the integration of health-related constructs - such as compliance and coping-style - and dynamic components of acceptance patterns in the theoretical explanation as well as in the modelling of acceptance and utilization behaviour with respect to medical technology.

A further note refers to the sample of this study. A comparably healthy sample, which was well equipped with ICT technology, was under study. Older adults in this sample represent the aging "baby boomer generation", which will become the main target group of future medical technologies. Thus, their attitudes and demands have to be considered by medical technology researchers and developers. However, apart from the main target group of "baby boomers", future acceptance studies should also integrate even older $(80+$ years $)$ and less healthy users in order to provide a higher sophisticated picture of medical technology acceptance [38].

Finally, an interdisciplinary user-centred approach is needed, which (1) explores and weighs the contributing factors of medical technology acceptance, (2) considers demands of a highly heterogeneous user group and the dynamic character of ageing and diseases in health-related utilization context, (3) identifies barriers and (4) derives practical interventions in order to promote higher acceptability of medical assistance.

Future studies will also have to investigate to what extent these outcomes may be generalized to specific illnesses or using contexts. A cross-cultural comparison of different societal aging concepts and their relation to acceptance of medical technology could also represent a valuable research topic. Furthermore, gender effects on acceptance of medical technology should be investigated in greater detail. Also, it will have to be found out, if the caveats reported by respondents vanish, when people get to know to these technologies.

\section{ACKNOWLEDGMENTS}

Authors would like to thank all participants, but especially the older ones, to patiently fill in the questionnaire and to allow us to gain insights into a sensible topic. This research was supported by the Excellence Initiative of the German federal and state governments. 


\section{REFERENCES}

[1] R. Wittenberg, A. Comas-Herrera, L. Pickard, and R. Hancock, „Future Demand for Long-Term Care in England“". PSSRU Research Summary, 2006

[2] S. Leonhardt, „Personal Healthcare Devices“. In: Mekherjee, S., et al. (eds.) Malware: Hardware Technology Drivers of Ambient Figure 6. Extent of pro arguments towards the usage of medical technology

[3] M. Weiner, C.M. Callahan, W.M. Tierney, M. Overhage, B. Mamlin, and A. Dexter, „Using Information Technology To Improve the Health Care of Older Adults". Ann. Intern. Med. 139, pp. 430-436, 2003.

[4] J.K.H Tan: Healthcare information systems \& informatics: research and practices, Hershey 2008

[5] P. Starr, „Smart technology, stunted policy: developing health information networks". Health Affairs 16(3), pp. 91-105, 1997.

[6] A. Lymberis, „Smart wearable systems for personalised health management: current R\&D and future challenges". Engineering in Medicine and Biology Society. In: Proceedings of the 25th Annual International Conference, vol. 4, pp. 3716-3719. IEEE, Los Alamitos, 2003.

[7] S.J. Czaja, J. Sharit, „Age Differences in Attitudes Toward Computers“. Journal of Gerontology 5, pp. 329-340, 1998

[8] A. Holzinger, K. Schaupp, K., W. Eder-Halbedl, „An Investigation on Acceptance of Ubiquitous Devices for the Elderly in a Geriatric Hospital Environment: Using the Example of Person Tracking". In: Proc. 11th International Conference on Computers Helping People with Special Needs, Berlin: Springer, 2008.

[9] K. Arning, and M. Ziefle, "Understanding differences in PDA acceptance and performance". Computers in Human Behaviour, 23(6), pp. 2904-2927, 2007.

[10] W. Wilkowska, and M. Ziefle, "Which factors form older adults' acceptance of mobile information and communication technologies?" In A. Holzinger \& K. Miesenberger (Eds.). Human-Computer Interaction for elnclusion, pp. 81-101, Berlin: Springer, 2009.

[11] W. Wilkowska, M. Ziefle, and K. Arning, "Older adults' navigation performance when using small-screen devices: does a tutor help?" Proceedings of the 9th International Conference on Work with Computer Systems, WWCS 2009, Beijing, China, 2009.

[12] M. Ziefle, U. Schroeder, J. Strenk, and T. Michel, „How young and older users master the use of hyperlinks in small screen devices“. Proc. of the SIGCHI conference on Human factors in computing systems 2007, pp. 307-316. ACM, New York, 2007.

[13] M. Ziefle, and S. Bay, „Transgenerational Designs in Mobile Technology“. In: Lumsden, J. (ed.) Handbook of Research on User Interface Design and Evaluation for Mobile Technology, pp. 122-140. IGI Global, 2008 .

[14] K. Arning, and M. Ziefle, "Cognitive and personal predictors for PDA navigation performance." Behaviour and Information Technology, 28 (3), pp. $251-263,2009$

[15] G. Beier, "Locus of control when interacting with technology" [Kontrollüberzeugungen im Umgang mit Technik]. Report Psychologie, 24, pp 684-693, 1999.

[16] J.C. Marquie, L. Jourdan-Boddaert, and N. Huet, "Do older adults underestimate their actual computer knowledge?" Behaviour and Information Technology 21(4), pp. 273-280, 2002.

[17] J.M. Noyes, and M.CA. Sheard, "Designing for older adults - are they a special group?" In: Universal Access in $\mathrm{HCI}$ : Inclusive Design in the Information Society, pp. 877-881. Lawrence Erlbaum, Mahwah, 2003.

[18] A.S. Melenhorst, W.A. Rogers, and E.C. Caylor, "The use of communication technologies by older adults: Exploring the benefits from an users perspective". In: Proc. of the Human Factors and Ergonomics Society 45th Annual Meeting, 2001.

[19] F.D. Davis, „Perceived Usefulness, Perceived Ease of Use, and User Acceptance of Information Technology“. MIS Quarterly 13, pp. 319337, 1989.

[20] V. Venkatesh, M.G. Morris, and F.D. Davis, „A Theoretical Extension of the Technology Acceptance Model: Four Longitudinal Field Studies". Management Science 46, pp. 186-204, 2000.

[21] V. Venkatesh, M.G. Morris, and F.D Davis,., „User acceptance of information technology: Toward a unified view“". MIS Quarterly 27, 3,
2003

[22] S. Gaul, M. Ziefle, W. Wilkowska, K. Arning, C. Röcker, K. Kasugai, and E.-M. Jakobs, "Technikakzeptanz als integraler Bestandteil der Entwicklung medizintechnischer Produkte" [technology acceptance as an integral part of the development of technical products]. Deutscher AAL-Kongress Assistenzsysteme im Dienste des Menschen. Zuhause und unterwegs, 2010.

[23] K. Arning, and M. Ziefle, "Different perspectives on technology acceptance: The role of technology type and age". In A. Holzinger \& K Miesenberger (Eds.). Human-Computer Interaction for eInclusion, pp. 20-41, Berlin: Springer, 2009

[24] K. Arning, and M. Ziefle: „Comparing apples and oranges? Exploring users' acceptance of ICT and eHealth applications". International Conference on Health Care Systems, Ergonomics, and Patient Safety, HEPS, 2008

[25] A. Calero-Valdez, M. Ziefle, U. Schroeder, A. Horstmann, and D. Herding, "Effects of aging and and domain knowledge on usability in small screen devices for diabetes patients". In A. Holzinger \& $\mathrm{K}$ Miesenberger (Eds.). Human-Computer Interaction for eInclusion, pp. 366-386, Berlin: Springer, 2009.

[26] E.V. Wilson, and N.K. Lankton, „Modeling patients' acceptance of provider-delivered e-health ". Journal of the American Medical Informatics Association 11, pp. 241-248, 2004.

[27] S. Gaul, and M. Ziefle, "Smart home technologies: insights into generation-specific acceptance motives". In A. Holzinger \& $\mathrm{K}$ Miesenberger (Eds.). Human-Computer Interaction for eInclusion, pp 312-332, Berlin: Springer, 2009.

[28] A. Holzinger, G. Searle, and A. Nischelwitzer, "On some Aspects of Improving Mobile Applications for the Elderly". In: Stephanidis, C (ed.), pp. 923-932. Springer, Heidelberg, 2007.

[29] R. Sackmann, and A. Weymann, "Die Technisierung des Alltags Generationen und technische Innovationen" [mechanization of daily life- generations and technical innovations]. Frankfurt, Germany: Campus, 1994

[30] M. Docampo Rama, H. d. Ridder \& H. Bouma, "Technology generation and Age in using layered user interfaces." Gerontechnology, 1(1), pp $25-40,2001$

[31] C. J Tully, "Growing Up in Technological Worlds. How modern technologies shape the modern lives of young people." In: Bulletin of Science, Technology \& Society, 64, pp. 444-456, 2003

[32] G. Demiris, B. K. Hensel, M. Skubic, and M. Rantz, "Senior residents' perceived need of and preferences for "smart home" sensor technologies". International Journal of Technology Assessment in Health Care 24, pp. 120-124, 2008

[33] Z. Zimmer, and N.L. Chappell, "Receptivity to new technology among older adults". Disability and Rehabilitation 21 (5/6), pp. 222-230, 1999.

[34] E.D. Mynatt, and W.A. Rogers, "Developing technology to support the functional independence of older adults". Ageing International 27(1) pp. 24-41, 2001

[35] C.S. Carver, M.F. Scheier, and J.K. Weintraub, "Assessing Coping Strategies: A Theoretically Based Approach". Journal of Personality and Social Psychology, 56(2) pp. 267-283, 1989.

[36] C. Shaw, "A framework for the study of coping, illness behaviour and outcomes. Methodological Issues". Nursing Research. Journal of Advanced Nursing. 29(5) pp. 1246-1255, 1999.

[37] P. Hampel, and F. Petermann, "Perceived stress, coping, and adjustment in adolescents". Journal of Adolescent Health, 38(4) pp. 409-415, 2006

[38] F. Alagöz, W. Wilkowska, D. Roefe, L. Klack, M. Ziefle \& T. SchmitzRode, "Technik ohne Herz? Nutzungsmotive und Akzeptanzbarrieren medizintechnischer Systeme aus der Sicht von Kunstherzpatienten." [Technolgy without heart? Using motives and acceptance barriers from the persective of patient with artifical hearts]. Deutscher AALKongress "Assistenzsysteme im Dienste des Menschen. Zuhause und unterwegs", Berlin, 2010

[39] W. Wilkowska, and M. Ziefle (2010), "User diversity as a challenge for the integration of medical technology into future home environments" In M. Ziefle \& C, Röcker (Eds). Human-Centred Design of eHalth Technologies. Concepts, methods and Applications. Hersehy, P.A. IGI Global, in press. 
Digital Object Identifier: 10.4108/ICST.PERVASIVEHEALTH2010.8859

http://dx.doi.org/10.4108/ICST.PERVASIVEHEALTH2010.8859 